\title{
Sequential Electrostatic Assembly of a Polymer Surfactant Corona Increases Activity of the Phosphotriesterase arPTE
}

\author{
William H. Zhang, ${ }^{\dagger}$ Benjamin M. Carter, ${ }^{\dagger}$ Graham J. Day, ${ }^{\dagger}$ Norman Govan, ${ }^{\ddagger}$ Colin Jackson, ${ }^{*}, \S_{(1)}$ \\ and Adam W. Perriman* ${ }^{\dagger} \dagger$ \\ ${ }^{\dagger}$ University of Bristol, School of Cellular and Molecular Medicine, Bristol BS8 1TD, United Kingdom \\ ${ }^{\ddagger}$ Defence Science and Technology Laboratory, Salisbury SP4 0JQ, United Kingdom \\ ${ }^{\S}$ Australian National University, Research School of Chemistry, Canberra ACT 2601, Australia
}

Supporting Information

\begin{abstract}
We present a new methodology for the generation of discrete molecularly dispersed enzymepolymer-surfactant bioconjugates. Significantly, we demonstrate that $>3$-fold increase in the catalytic efficiency of the diffusion-limited phosphotriesterase arPTE can be achieved through sequential electrostatic addition of cationic and anionic polymer surfactants, respectively. Here, the polymer surfactants assemble on the surface of the enzyme via ion exchange to yield a compact corona. The observed rate enhancement is consistent with a mechanism whereby the
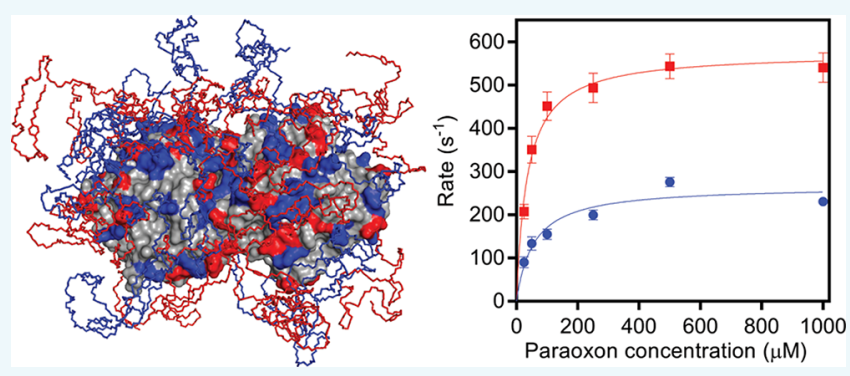
polymer-surfactant corona gives rise to a decrease in the dielectric constant in the vicinity of the active site of the enzyme, accelerating the rate-determining product diffusion step. The facile methodology has significant potential for increasing the efficiency of enzymes and could therefore have a substantially positive impact for industrial enzymology.
\end{abstract}

$\mathrm{P}$ hosphotriesterases (PTEs, also known as organophosphate hydrolases) have evolved to rapidly detoxify organophosphates (OPs). This has attracted significant interest as a potential means to counteract poisoning from OP-based chemical warfare agents and pesticides. ${ }^{1,2}$ These highly toxic compounds are still used as a tool of conflict and covert action, with recent examples including sarin attacks in Syria and the use of a Novichock agent in the United Kingdom. ${ }^{3}$ The effectiveness of PTEs is directly dependent on the rate at which they can detoxify these compounds, as well as the lifetime of the enzyme. ${ }^{4}$ The real-world performance of enzymes can often be improved through covalent modifications such as PEGylation, 5,6 or immobilization and entrapment of enzymes at surfaces. $^{7-9}$ Indeed, enzyme immobilization can offer great improvements to thermostability, enable enzymes to be integrated into large-scale high-throughput production systems, and, crucially, allow these enzymes to be recycled multiple times. ${ }^{10-12}$ However, these approaches often impart detrimental effects such as a decrease in enzyme activity, which can preclude an enzyme from practical use. ${ }^{0,11,13,14}$ Here, this decrease in activity can result from surface-induced denaturation, obstruction of the active site, or reduction in the rate of substrate/product diffusion.

We have previously developed a methodology to modify protein surfaces via electrostatic assembly of a polymer surfactant corona. ${ }^{15-18}$ This process involves chemical cationization via nucleophilic addition of diamines to the solvent-exposed acidic residues to generate supercationic proteins, followed by electrostatic grafting of anionic polymer surfactant molecules to the surface. Once formed, these complexes were ionically stable, as verified through analytical ultracentrifugation in the presence of high salt, ${ }^{17,19}$ and similarly, the presence of fatty substrates such as lipids does not dissociate the enzyme-surfactant complex. ${ }^{15}$ Significantly, the resulting hybrid constructs were used to produce a portfolio of new biomaterials that exhibited a wide range of interesting properties, including biologically active solvent-free biofluids with extreme thermostability, ${ }^{15,17,18}$ hierarchically self-assembled membrane films with recyclable catalytic activities, $^{20,21}$ and artificial cell membrane-binding proteins with oxygen delivery and extracellular matrix forming capacities. $^{22,23}$ However, as commonly reported for other covalent approaches to protein modification, the chemical cationization required to supercharge the proteins resulted in a significant loss in protein structure and enzymatic activity. ${ }^{15,22,24}$ Accordingly, we describe a noncovalent approach to generate molecularly dispersed protein-polymer surfactant bioconjugates (Figure 1). This new methodology involves sequential electrostatic grafting of PEG-based cationic and anionic surfactants via ion exchange to the naturally occurring charged residues on the surface of the enzyme. This gives rise to monodispersed enzyme-polymer surfactant complexes (denoted [Enzyme $]\left[\mathrm{S}^{+}\right]\left[\mathrm{S}^{-}\right]$) that are analogous to previously

Received: October 2, 2019

Revised: October 9, 2019

Published: October 11, 2019 


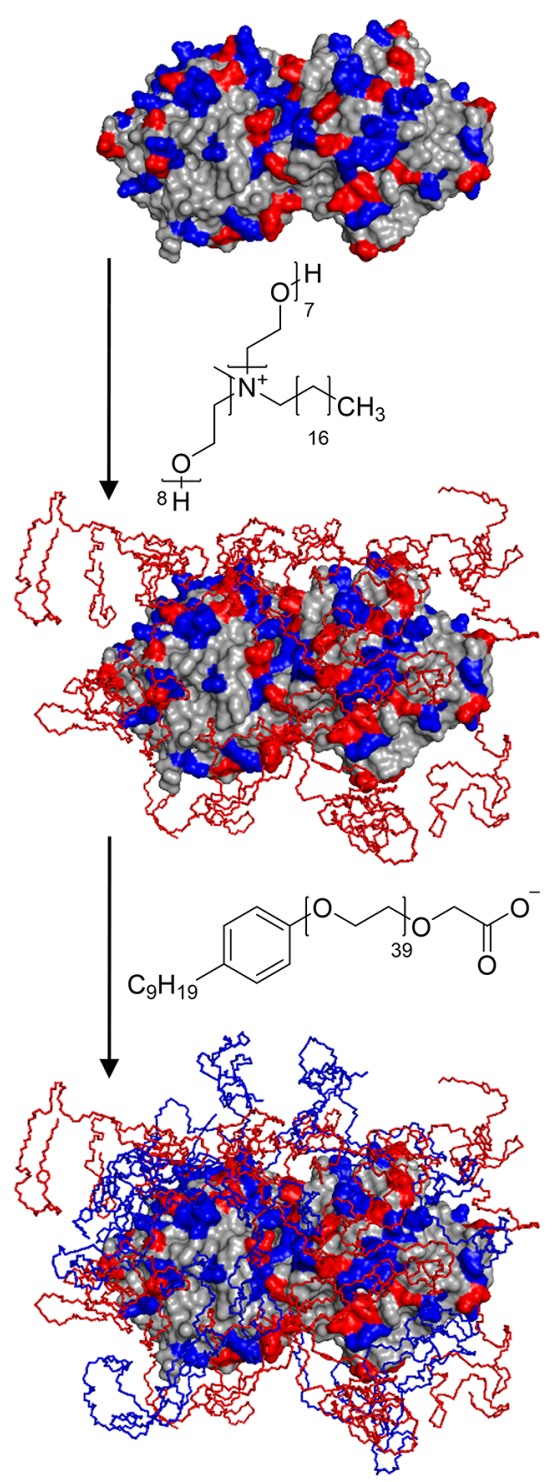

Figure 1. Schematic depicting the conjugation process, involving the sequential electrostatic addition of polymer-surfactants. First, cationic surfactants (Ethoquad, red) are complexed to an unmodified protein (arPTE shown above) through electrostatic forces to the solvent exposed anionic amino acids (red sites on the protein). This is then followed by the addition of an anionic surfactant (oxidized IGEPAL, blue), which are likewise complexed to the protein through electrostatic interactions with the solvent exposed cationic amino acids (blue sites on the protein). The result is a surfactant corona that encapsulates the protein.

described bioconjugates, ${ }^{15,22}$ but can be readily produced without the need for covalent modification. Significantly, for the Agrobacterium radiobacter phosphotriesterase (arPTE), ${ }^{25}$ we observe a more-than 3-fold increase in the catalytic efficiency by optimizing the composition of the polymer surfactant corona.

Kinetic assays of paraoxon hydrolysis using $[\operatorname{arPTE}]\left[\mathrm{S}^{+}\right]\left[\mathrm{S}^{-}\right]$ were performed over a range of anionic polymer surfactant molecular weights, with higher molecular weight surfactants tending toward higher activities (Figure S1). Moreover, no activity enhancement was observed after the addition of only the cationic surfactant Ethoquad (Figure S1). Reversing the order of addition of the surfactants (i.e., $\left[\mathrm{S}^{-}\right]\left[\mathrm{S}^{+}\right]$) for some surfactants resulted in enzyme aggregation and precipitation and, accordingly, was not pursued further. Previous computational models reveal the formation of micelle-like structures, which limits the interactions between the charged heads groups of the different surfactants and thus facilitates the formation of the corona despite the potential for surfactantsurfactant ionic interactions. ${ }^{26}$ The greatest enhancement to catalytic activity occurred after the sequential addition of Ethoquad followed by oxidized IGEPAL-890 (Figures 2 and
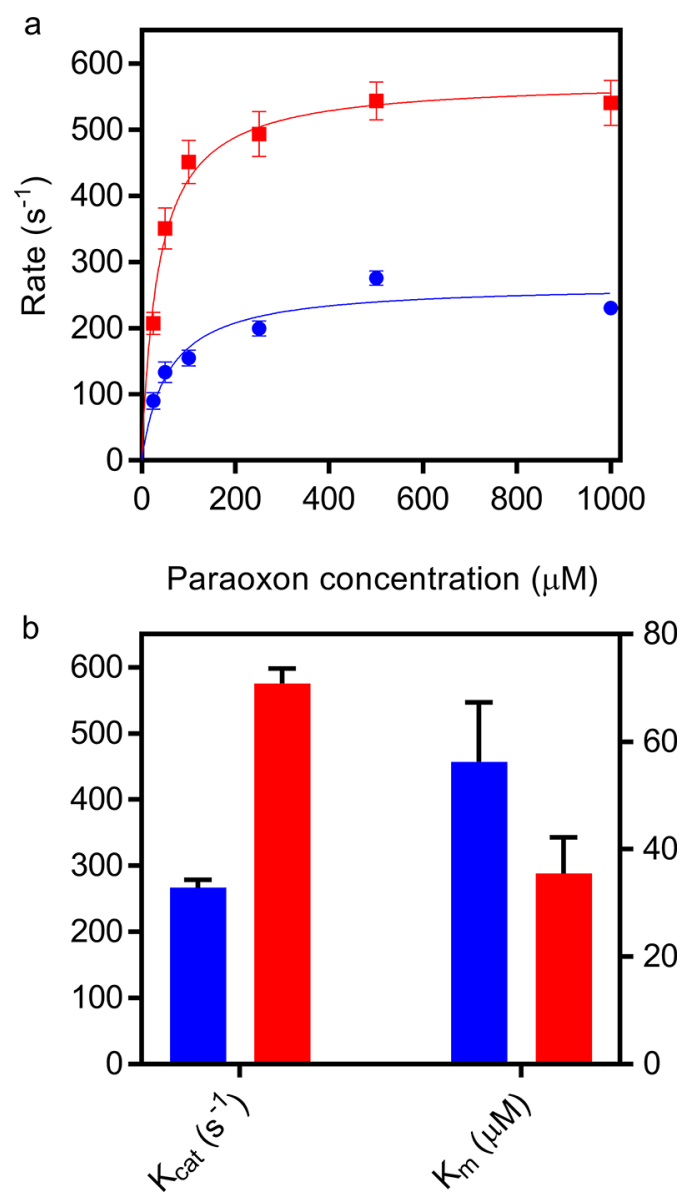

Figure 2. (a) Michaelis-Menten curve of the enzyme arPTE (blue) compared and $[\operatorname{arPTE}]\left[\mathrm{S}^{+}\right]\left[\mathrm{S}^{-}\right]$(red) demonstrating a large increase to catalytic rate at room temperature. Assays were performed under the conditions described in the supplementary methods. (b) The corresponding $k_{\text {cat }}$ and $K_{\mathrm{m}}$ of arPTE and $[\operatorname{arPTE}]\left[\mathrm{S}^{+}\right]\left[\mathrm{S}^{-}\right]$derived from the Michaelis-Menten curve shown in in (a).

S2), which resulted in a 2-fold increase in the substrate turnover rate $\left(k_{\text {cat }}\right)$ when compared to unmodified arPTE (267 $\pm 12 \mathrm{~s}^{-1}$ to $\left.575 \pm 23 \mathrm{~s}^{-1}\right)$. Moreover, this was accompanied by an improvement in the substrate binding affinity $\left(K_{\mathrm{m}} ; 56 \pm 10\right.$ to $36 \pm 6 \mu \mathrm{M}$ ), which translates to a more-than 3-fold increase in the specificity constant (catalytic efficiency, $k_{\text {cat }} / K_{\mathrm{m}} ; 4.7 \times$ $10^{6}$ to $1.6 \times 10^{7} \mathrm{M}^{-1} \mathrm{~s}^{-1}$ ). Accordingly, this protocol was used for all subsequent experiments, and the resulting bioconjugate is hereafter denoted by $[\operatorname{arPTE}]\left[\mathrm{S}^{+}\right]\left[\mathrm{S}^{-}\right]$.

To verify the polymer-surfactant binding to the surface of arPTE, synchrotron radiation small-angle X-ray scattering (SRSAXS) experiments were performed to evaluate the dimensions of the unmodified and surfactant complexed enzyme $\left([\operatorname{arPTE}]\left[\mathrm{S}^{+}\right]\left[\mathrm{S}^{-}\right]\right)$. A $12.6 \AA$ increase in the radial average $\left(r_{\text {ave }}\right)$ was calculated from the pair-distance distribution function $(P(r)$, Figure $3 \mathrm{~A})$ of $[\operatorname{arPTE}]\left[\mathrm{S}^{+}\right]\left[\mathrm{S}^{-}\right]$relative to 


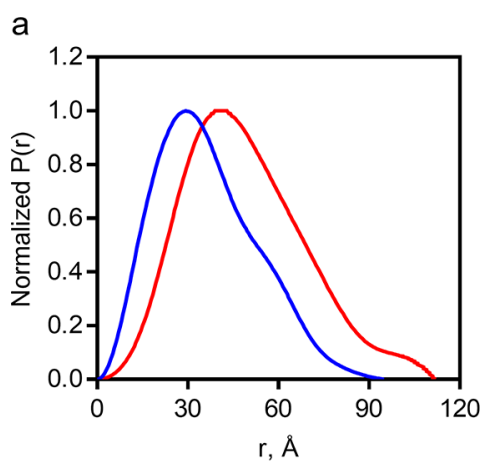

b
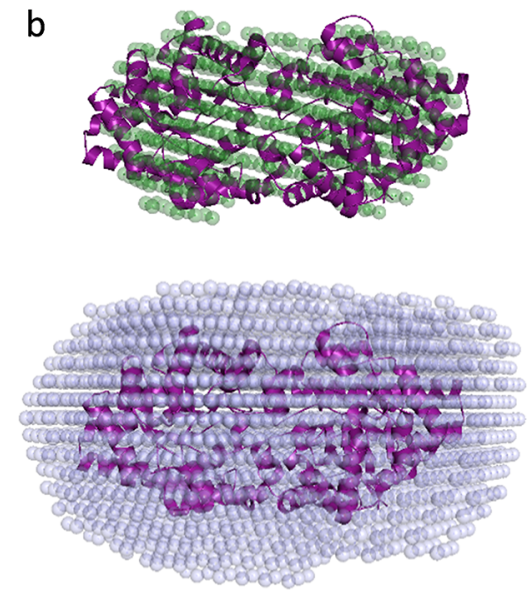

Figure 3. (a) Pair-distance distribution function $(P(r))$ of arPTE (blue) and $[\operatorname{arPTE}]\left[\mathrm{S}^{+}\right]\left[\mathrm{S}^{-}\right]$(red) obtained through SR-SAXS. The surfactant conjugation process increases the radial average $\left(r_{\text {ave }}\right)$ of the enzyme from 36.2 to $48.8 \AA$. (b) Crystal structure of arPTE (PDB ID: 2D2J, purple) superimposed on the bead-model obtained from SRSAXS analysis of arPTE (green) and $[\operatorname{arPTE}]\left[\mathrm{S}^{+}\right]\left[\mathrm{S}^{-}\right]$(blue). The models confirm that the oligomeric state of the enzyme is still maintained after conjugation with the surfactant corona, and that the surfactant creates a consistent shell around the enzyme.

arPTE, which is comparable to computational models based on the analogous chemically cationized single-surfactant systems. ${ }^{26}$ Additionally, there was a small change in the Porod exponent between $\operatorname{arPTE}$ and $[\operatorname{arPTE}]\left[\mathrm{S}^{+}\right]\left[\mathrm{S}^{-}\right]$(3.8 to 3.5, Table S1), which is to be expected due to the addition of flexible surfactant chains. Bead models produced from the SRSAXS analyses revealed that the size and shape of the unmodified arPTE is commensurate with the published crystal structures of the dimeric enzyme (PDB ID: 2D2J), and that $[\operatorname{arPTE}]\left[\mathrm{S}^{+}\right]\left[\mathrm{S}^{-}\right]$has an increased size corresponding to the addition of a compact polymer surfactant corona to the dimer (Figures $3 \mathrm{~B}$ and S3A,B). This size increase supports an electrostatically driven assembly process to form an encapsulating polymer surfactant layer, resulting in discrete, monodispersed surfactant-enzyme dimer complexes. ${ }^{27}$

Circular dichroism (CD) measurements revealed superimposable spectra for arPTE and $[\operatorname{arPTE}]\left[\mathrm{S}^{+}\right]\left[\mathrm{S}^{-}\right]$(Figure S4A), which indicated that surfactant complexation did not affect the secondary structure. This suggests that the rate enhancement did not occur via fortuitous stabilization of a structural conformation, although conformational changes beyond the resolution of CD cannot be discounted.

The observed catalytic efficiency of many enzymes are dependent on other extraneous contributions, such as surfaceinduced deactivation. ${ }^{28}$ This effect can be significant when working with enzymes at very low concentrations, as is necessary to collect the linear initial rate for highly efficient enzymes such as arPTE. Experimentally, these adsorption effects can be prevented with the addition of bovine serum albumin (BSA) to block nonspecific protein binding. ${ }^{29}$ Accordingly, both arPTE and $[\operatorname{arPTE}]\left[\mathrm{S}^{+}\right]\left[\mathrm{S}^{-}\right]$were assayed against paraoxon with and without the presence of $0.1 \% \mathrm{w} / \mathrm{v}$ BSA. The addition of BSA did not initially result in a change in the catalytic activity in either system (assay periods $<10 \mathrm{~min}$ ) (Figure 4A). However, assays performed over a $4 \mathrm{~h}$ period

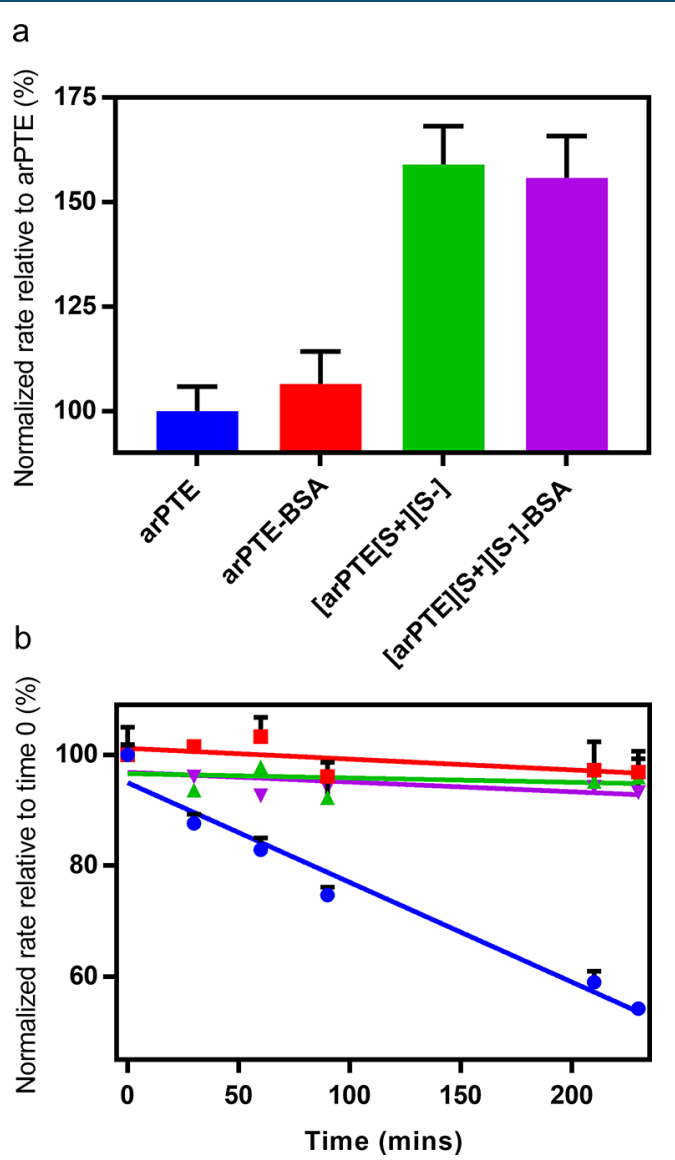

Figure 4. (a) Normalized catalytic rate $\left(k_{\text {cat }}\right)$ of arPTE and $[\operatorname{arPTE}]\left[\mathrm{S}^{+}\right]\left[\mathrm{S}^{-}\right]$at room temperature with and without the presence of $0.1 \% \mathrm{w} / \mathrm{v}$ BSA, showing that BSA itself does not appear to directly influence catalytic rate. (b) Activity of a stock of $4 \mathrm{nM}$ enzyme over time at room temperature, showing that hydrophobic denaturation can significantly affect the observed rate of arPTE (blue) over extended periods of time. arPTE with BSA (red), $[\operatorname{arPTE}]\left[\mathrm{S}^{+}\right]\left[\mathrm{S}^{-}\right]$ (green), and $[\operatorname{arPTE}]\left[\mathrm{S}^{+}\right]\left[\mathrm{S}^{-}\right]$with BSA (purple) do not exhibit this loss in activity. All assays were performed as described in the Supporting Information in a buffer of $30 \mathrm{mM}$ HEPES, $100 \mu \mathrm{M}$ cobalt chloride at $\mathrm{pH} 8.0$.

showed a gradual decay in the activity of arPTE, which did not occur for $[\operatorname{arPTE}]\left[\mathrm{S}^{+}\right]\left[\mathrm{S}^{-}\right]$, $[\operatorname{arPTE}]\left[\mathrm{S}^{+}\right]\left[\mathrm{S}^{-}\right]$with $0.1 \% \mathrm{w} / \mathrm{v}$ BSA, or arPTE with $0.1 \%$ w/v BSA (Figure $4 \mathrm{~B}$ ). To investigate if the loss in activity of the native enzyme was due to slow unfolding (rather than surface-induced deactivation), a timedependent circular dichroism thermostability study of arPTE and $[\operatorname{arPTE}]\left[\mathrm{S}^{+}\right]\left[\mathrm{S}^{-}\right]$was performed (Figures $\mathrm{S} 4 \mathrm{~B}-\mathrm{C}$ ). While a high-temperature $C D$ gradient did show that $[\operatorname{arPTE}]\left[\mathrm{S}^{+}\right]\left[\mathrm{S}^{-}\right]$had a slight enhancement to overall thermostability, an isothermal time-course experiment at $40{ }^{\circ} \mathrm{C}$ 
showed that no slow denaturation of either $[\operatorname{arPTE}]\left[\mathrm{S}^{+}\right]\left[\mathrm{S}^{-}\right]$ or arPTE occurs even at temperatures elevated slightly above ambient conditions. Accordingly, this data supports a scenario where either the surfactant corona or BSA stabilized the enzyme, and where the presence of BSA did not enhance the activity of the enzyme, but rather, prevented the loss of activity over time. Moreover, this loss of activity would only be significant for assays conducted over long time periods, and therefore could only represent a small fraction of the improvement in the catalytic efficiency observed for [arPTE]$\left[\mathrm{S}^{+}\right]\left[\mathrm{S}^{-}\right]$.

Previous studies of PTEs have established that the rate limiting step of these high turnover rate enzymes is the diffusion of the reaction product away from the active site. ${ }^{30}$ It is therefore possible that the formation of a compact amphiphilic polymer-surfactant corona may accelerate the diffusion step via product partitioning through a reduction in the local dielectric constant at the active site. This mechanism is supported by the conserved tertiary and secondary structure reported above (verified through SAXS and CD respectively), and the positive correlation between the molecular weight of the surfactant and the enzymatic activity. This is not unprecedented, as an increase in activity has previously been noted post-modification of PTEs, ${ }^{31}$ with an in-depth study of PTE nanoparticle complexes also showing an increase in activity. $^{32,33}$ The authors attributed this to an increase in the diffusion of the product away from the active site, promoted by a change in the immediate microenvironment around the enzyme. Using the same theoretical model as Breger et al. that considers changes in substrate and product on and off rates, ${ }^{32}$ we show that our experimentally observed data is consistent with an increase to the product release/diffusion step, rather than a substrate binding step (Figure S5). Finally, we observe that compared to paraoxon, the magnitude of the rate enhancement is larger for coumaphos (Figures S6A,B), a substrate with a more hydrophobic product, further supporting the theory that diffusion of hydrophobic products is better enabled by the amphiphilic corona. Enzyme enhancement through substrate/product partitioning has been previously described, but through enzyme immobilization; ${ }^{34}$ thus, the retention of enzyme mobility is an important outcome. However, as alterations to the surface of arPTE can have an impact on activity, ${ }^{30,35}$ we cannot discount the possibility that there is some fortuitous enhancement of conformational mobility, resulting in an increase in the rate of product release. An additional consideration is a change in the oligomeric equilibrium between the monomer and dimer influencing the catalytic rate; however as we see a difference in the rate enhancement between different substrates, this is unlikely.

To further probe the effect of polymer surfactant complexation on enzyme structure and function, the dual surfactant complexation method was applied to three other PTEs: pdPTE-C23, $\alpha$-Esterase7 ( $\alpha$ Est7), and DFPase (Figure S7AC). ${ }^{36-38}$ Phosphotriesterase-C23 (pdPTE-C23) is a PTE mutant from Pseudomonas diminuta designed for greater catalytic efficiency against the $\mathrm{G}$ and $\mathrm{V}$ series nerve agents. ${ }^{36}$ $\alpha$ Est7 is a carboxylesterase that has evolved independently to break down a number of organophosphate pesticides and is structurally distinct from the PTE enzyme superfamily. ${ }^{37}$ Finally, DFPase, found in Loligo vulgaris, is capable of hydrolyzing diisopropylfluorophosphate (DFP), and like $\alpha$ Est7, is structurally distinct. ${ }^{38}$ All three enzymes successfully formed enzymatically active polymer surfactant-complexes through the dual-surfactant method. As with $[\operatorname{arPTE}]\left[\mathrm{S}^{+}\right]\left[\mathrm{S}^{-}\right]$, SR-SAXS confirmed the formation of discrete enzymepolymer surfactant complexes with compact coronas (Figure S7D-F). Interestingly, polymer-surfactant complexation resulted in a decrease in $k_{\text {cat }}$ and an increase in $K_{\mathrm{m}}$ for pdPTE-C23 and $\alpha$ Est7. As $\alpha$ Est7 has evolved to hydrolyze fatty ester substrates akin to the hydrophobic tails of the surfactant, this is likely a consequence of steric inhibition of the active site. $^{15,24}$ In a similar fashion, pdPTE-C23 has an engineered mutation of a phenylalanine residue to a glutamate (F132E) at the active site, ${ }^{36}$ which would promote inhibition via electrostatic binding of $\mathrm{S}^{+}$. To confirm that the observed inhibition was not due to denaturation and was a result of active site inhibition, we also assayed the activity after treating pdPTE-C23 with uncharged surfactants. As expected, at high surfactant concentrations ( $1 \% \mathrm{w} / \mathrm{v}$ of assay) pdPTE-C23 showed inhibition comparable to [pdPTE-C23] $\left[\mathrm{S}^{-}\right.$] (Figure S8). However, after dialysis, activity was restored to pdPTEC23 treated with uncharged surfactants, but not for [pdPTE$\mathrm{C} 23]\left[\mathrm{S}^{-}\right]$. This demonstrates that the decreased rate is through active site inhibition by the surfactant, and also verifies that the surfactant corona complex is maintained even at dilute concentrations. Finally, for DFPase we observed no change in affinity or rate between the unmodified enzyme and the bioconjugate $[\mathrm{DFPase}]\left[\mathrm{S}^{+}\right]\left[\mathrm{S}^{-}\right]$. As the rate limiting step of DFPase is the dissociation of fluorine from the phosphorus during the catalytic cycle, ${ }^{38}$ the lack of rate enhancement (or decrease) observed here supports our proposed mechanism of improved product off rate.

In conclusion, we have demonstrated that our electrostatic dual surfactant conjugation methodology can be readily applied to generate aqueous molecular dispersion of active enzyme-polymer surfactant complexes without the need for covalent modifications. Moreover, we show that the approach can be tuned to enhance the catalytic efficiency of arPTE by more than 3-fold, and we reconcile this improvement with an acceleration in the product diffusion rate via hydrophobic partitioning. We also show that the surface-bound polymer surfactant corona protects arPTE from surface-induced deactivation. Although we could readily apply our methodology to other PTEs to give catalytically active complexes, it is clear that rate enhancement is dependent on parameters such as catalytic mechanism, surface charge, hydrophobicity, and active site geometry. In principle, the use of amphiphilic coronas is compatible with other beneficial enzyme modifications such as immobilization. The covalent linkage of the surfactant or the enzyme to a surface may impart properties such as improved selectivity, ${ }^{34}$ and may enhance the enzyme beyond what is achievable through simple immobilization alone, but at the cost of enzyme mobility. With the correct selection of polymer-surfactants and rational enzyme design, it should be possible to improve the performance of industrially relevant enzymes under both aqueous and nonaqueous conditions. ${ }^{39,40}$

\section{ASSOCIATED CONTENT}

\section{S Supporting Information}

The Supporting Information is available free of charge on the ACS Publications website at DOI: 10.1021/acs.bioconjchem.9b00664. 
Experimental methods such as protein expression, synthesis and complexation, and assay procedures, as well as supplementary figures and tables (PDF)

\section{AUTHOR INFORMATION}

\section{Corresponding Authors}

*E-mail: chawp@bristol.ac.uk.

*E-mail: cjackson@rsc.anu.edu.au.

ORCID $\odot$

Colin Jackson: 0000-0001-6150-3822

Adam W. Perriman: 0000-0003-2205-9364

Notes

The authors declare no competing financial interest.

\section{ACKNOWLEDGMENTS}

This research was funded by the EPSRC (EP/N026586/1) that was awarded in collaboration with the Defence Science and Technology Laboratory (DSTL). We are grateful for the time allotment from Diamond, which allowed SR-SAXS to be performed at the Diamond Light Source I22 beamline, and SEC-SR-SAXS to be performed using the Diamond B21 mailin service. We would like to thank Jayne Ede and Ian Shortman from the Defence Science and Technology Laboratory (DSTL) for intellectual input and discussion. We would also like to thank Eleanor Campbell and Galen Corey (From the Australian National University) for supplying the arPTE and $\alpha$ Est7 plasmids, respectively.

\section{REFERENCES}

(1) Tsai, P. C., Fox, N., Bigley, A. N., Harvey, S. P., Barondeau, D. P., and Raushel, F. M. (2012) Enzymes for the homeland defense: optimizing phosphotriesterase for the hydrolysis of organophosphate nerve agents. Biochemistry 51, 6463-75.

(2) Jacquet, P., Daude, D., Bzdrenga, J., Masson, P., Elias, M., and Chabriere, E. (2016) Current and emerging strategies for organophosphate decontamination: special focus on hyperstable enzymes. Environ. Sci. Pollut. Res. 23, 8200-18.

(3) Vale, J. A., Marrs, T. O., and Maynard, R. C. (2018) Novichok: a murderous nerve agent attack in the UK. Clin. Toxicol. 56, 10931097.

(4) Gupta, R. D., Goldsmith, M., Ashani, Y., Simo, Y., Mullokandov, G., Bar, H., Ben-David, M., Leader, H., Margalit, R., Silman, I., et al. (2011) Directed evolution of hydrolases for prevention of G-type nerve agent intoxication. Nat. Chem. Biol. 7, 120-5.

(5) Swierczewska, M., Lee, K. C., and Lee, S. (2015) What is the future of PEGylated therapies? Expert Opin. Emerging Drugs 20, 5316.

(6) Dozier, J. K., and Distefano, M. D. (2015) Site-Specific PEGylation of Therapeutic Proteins. Int. J. Mol. Sci. 16, 25831-64.

(7) Rabuka, D. (2010) Chemoenzymatic methods for site-specific protein modification. Curr. Opin. Chem. Biol. 14, 790-6.

(8) Zhang, Y. F., Ge, J., and Liu, Z. (2015) Enhanced Activity of Immobilized or Chemically Modified Enzymes. ACS Catal. 5, 45034513.

(9) Denard, C. A., Ren, H., and Zhao, H. (2015) Improving and repurposing biocatalysts via directed evolution. Curr. Opin. Chem. Biol. $25,55-64$.

(10) DiCosimo, R., McAuliffe, J., Poulose, A. J., and Bohlmann, G. (2013) Industrial use of immobilized enzymes. Chem. Soc. Rev. 42, 6437-74.

(11) Sheldon, R. A., and Brady, D. (2018) The limits to biocatalysis: pushing the envelope. Chem. Commun. (Cambridge, U. K.) 54, 60886104.

(12) Sheldon, R. A., and Woodley, J. M. (2018) Role of Biocatalysis in Sustainable Chemistry. Chem. Rev. 118, 801-838.
(13) Lawrence, P. B., and Price, J. L. (2016) How PEGylation influences protein conformational stability. Curr. Opin. Chem. Biol. 34, $88-94$.

(14) Keefe, A. J., and Jiang, S. (2012) Poly(zwitterionic)protein conjugates offer increased stability without sacrificing binding affinity or bioactivity. Nat. Chem. 4, 59-63.

(15) Brogan, A. P. S., Sharma, K. P., Perriman, A. W., and Mann, S. (2014) Enzyme activity in liquid lipase melts as a step towards solvent-free biology at $150^{\circ} \mathrm{C}$. Nat. Commun. 5, 5058.

(16) Gallat, F. X., Brogan, A. P., Fichou, Y., McGrath, N., Moulin, M., Hartlein, M., Combet, J., Wuttke, J., Mann, S., Zaccai, G., et al. (2012) A polymer surfactant corona dynamically replaces water in solvent-free protein liquids and ensures macromolecular flexibility and activity. J. Am. Chem. Soc. 134, 13168-71.

(17) Perriman, A. W., Colfen, H., Hughes, R. W., Barrie, C. L., and Mann, S. (2009) Solvent-free protein liquids and liquid crystals. Angew. Chem., Int. Ed. 48, 6242-6.

(18) Perriman, A. W., Brogan, A. P., Colfen, H., Tsoureas, N., Owen, G. R., and Mann, S. (2010) Reversible dioxygen binding in solventfree liquid myoglobin. Nat. Chem. 2, 622-6.

(19) Xiao, W. J., Green, T. I. P., Liang, X. W., Delint, R. C., Perry, G., Roberts, M. S., Le Vay, K., Back, C. R., Ascione, R., Wang, H. L., et al. (2019) Designer artificial membrane binding proteins to direct stem cells to the myocardium. Chem. Sci. 10, 7610-7618.

(20) Sharma, K. P., Collins, A. M., Perriman, A. W., and Mann, S. (2013) Enzymatically active self-standing protein-polymer surfactant films prepared by hierarchical self-assembly. Adv. Mater. 25, 2005-10.

(21) Farrugia, T., Perriman, A. W., Sharma, K. P., and Mann, S. (2017) Multi-enzyme cascade reactions using protein-polymer surfactant self-standing films. Chem. Commun. (Cambridge, U. K.) 53, 2094-2097.

(22) Armstrong, J. P. K., Shakur, R., Horne, J. P., Dickinson, S. C., Armstrong, C. T., Lau, K., Kadiwala, J., Lowe, R., Seddon, A., Mann, S., et al. (2015) Artificial membrane-binding proteins stimulate oxygenation of stem cells during engineering of large cartilage tissue. Nat. Commun. 6, 7405.

(23) Deller, R. C., Richardson, T., Richardson, R., Bevan, L., Zampetakis, I., Scarpa, F., and Perriman, A. W. (2019) Artificial cell membrane binding thrombin constructs drive in situ fibrin hydrogel formation. Nat. Commun. 10, 1887.

(24) Perez, B., Coletta, A., Pedersen, J. N., Petersen, S. V., Periole, X., Pedersen, J. S., Sessions, R. B., Guo, Z., Perriman, A., and Schiott, B. (2018) Insight into the molecular mechanism behind PEGmediated stabilization of biofluid lipases. Sci. Rep. 8, 12293.

(25) Ely, F., Hadler, K. S., Gahan, L. R., Guddat, L. W., Ollis, D. L., and Schenk, G. (2010) The organophosphate-degrading enzyme from Agrobacterium radiobacter displays mechanistic flexibility for catalysis. Biochem. J. 432, 565-73.

(26) Brogan, A. P., Sessions, R. B., Perriman, A. W., and Mann, S. (2014) Molecular dynamics simulations reveal a dielectric-responsive coronal structure in protein-polymer surfactant hybrid nanoconstructs. J. Am. Chem. Soc. 136, 16824-31.

(27) Zhang, Y., Patil, A. J., Perriman, A. W., and Mann, S. (2013) Enhanced catalytic activity in organic solvents using molecularly dispersed haemoglobin-polymer surfactant constructs. Chem. Commun. (Cambridge, U. K.) 49, 9561-3.

(28) Brode, P. F., Erwin, C. R., Rauch, D. S., Lucas, D. S., and Rubingh, D. N. (1994) Enzyme Behavior at Surfaces - Site-Specific Variants of Subtilisin Bpn' with Enhanced Surface Stability. J. Biol. Chem. 269, 23538-23543.

(29) Goebel-Stengel, M., Stengel, A., Tache, Y., and Reeve, J. R., Jr. (2011) The importance of using the optimal plasticware and glassware in studies involving peptides. Anal. Biochem. 414, 38-46.

(30) Jackson, C. J., Foo, J. L., Tokuriki, N., Afriat, L., Carr, P. D., Kim, H. K., Schenk, G., Tawfik, D. S., and Ollis, D. L. (2009) Conformational sampling, catalysis, and evolution of the bacterial phosphotriesterase. Proc. Natl. Acad. Sci. U. S. A. 106, 21631-6.

(31) Kim, M., Gkikas, M., Huang, A., Kang, J. W., Suthiwangcharoen, N., Nagarajan, R., and Olsen, B. D. (2014) 
Enhanced activity and stability of organophosphorus hydrolase via interaction with an amphiphilic polymer. Chem. Commun. (Cambridge, U. K.) 50, 5345-8.

(32) Breger, J. C., Ancona, M. G., Walper, S. A., Oh, E., Susumu, K., Stewart, M. H., Deschamps, J. R., and Medintz, I. L. (2015) Understanding How Nanoparticle Attachment Enhances Phosphotriesterase Kinetic Efficiency. ACS Nano 9, 8491-503.

(33) Hondred, J. A., Breger, J. C., Garland, N. T., Oh, E., Susumu, K., Walper, S. A., Medintz, I. L., and Claussen, J. C. (2017) Enhanced enzymatic activity from phosphotriesterase trimer gold nanoparticle bioconjugates for pesticide detection. Analyst 142, 3261-3271.

(34) Rodrigues, R. C., Ortiz, C., Berenguer-Murcia, A., Torres, R., and Fernandez-Lafuente, R. (2013) Modifying enzyme activity and selectivity by immobilization. Chem. Soc. Rev. 42, 6290-307.

(35) Campbell, E., Kaltenbach, M., Correy, G. J., Carr, P. D., Porebski, B. T., Livingstone, E. K., Afriat-Jurnou, L., Buckle, A. M., Weik, M., Hollfelder, F., et al. (2016) The role of protein dynamics in the evolution of new enzyme function. Nat. Chem. Biol. 12, 944-950. (36) Cherny, I., Greisen, P., Jr., Ashani, Y., Khare, S. D., Oberdorfer, G., Leader, H., Baker, D., and Tawfik, D. S. (2013) Engineering Vtype nerve agents detoxifying enzymes using computationally focused libraries. ACS Chem. Biol. 8, 2394-403.

(37) Jackson, C. J., Liu, J. W., Carr, P. D., Younus, F., Coppin, C., Meirelles, T., Lethier, M., Pandey, G., Ollis, D. L., Russell, R. J., et al. (2013) Structure and function of an insect alpha-carboxylesterase (alphaEsterase7) associated with insecticide resistance. Proc. Natl. Acad. Sci. U. S. A. 110, 10177-82.

(38) Wymore, T., Field, M. J., Langan, P., Smith, J. C., and Parks, J. M. (2014) Hydrolysis of DFP and the nerve agent (S)-sarin by DFPase proceeds along two different reaction pathways: implications for engineering bioscavengers. J. Phys. Chem. B 118, 4479-89.

(39) Klibanov, A. M. (2001) Improving enzymes by using them in organic solvents. Nature 409, 241-6.

(40) Ke, T., and Klibanov, A. M. (1998) On enzymatic activity in organic solvents as a function of enzyme history. Biotechnol. Bioeng. $57,746-750$. 